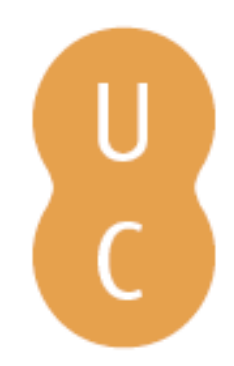

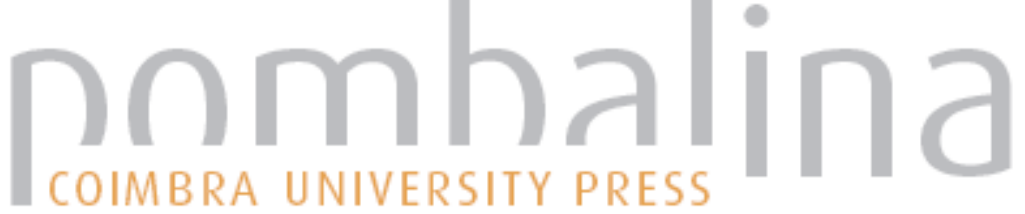

\section{El anciano sirviente de Fenicias}

Autor(es): $\quad$ Morenilla, Carmen

Publicado por: Imprensa da Universidade de Coimbra; Annablume

URL

persistente: URI:http://hdl.handle.net/10316.2/40892

DOI: $\quad$ DOl:https://doi.org/10.14195/978-989-26-1278-2_9

Accessed : $\quad$ 26-Apr-2023 16:32:18

A navegação consulta e descarregamento dos títulos inseridos nas Bibliotecas Digitais UC Digitalis, UC Pombalina e UC Impactum, pressupõem a aceitação plena e sem reservas dos Termos e Condições de Uso destas Bibliotecas Digitais, disponíveis em https://digitalis.uc.pt/pt-pt/termos.

Conforme exposto nos referidos Termos e Condições de Uso, o descarregamento de títulos de acesso restrito requer uma licença válida de autorização devendo o utilizador aceder ao(s) documento(s) a partir de um endereço de IP da instituição detentora da supramencionada licença.

Ao utilizador é apenas permitido o descarregamento para uso pessoal, pelo que o emprego do(s) título(s) descarregado(s) para outro fim, designadamente comercial, carece de autorização do respetivo autor ou editor da obra.

Na medida em que todas as obras da UC Digitalis se encontram protegidas pelo Código do Direito de Autor e Direitos Conexos e demais legislação aplicável, toda a cópia, parcial ou total, deste documento, nos casos em que é legalmente admitida, deverá conter ou fazer-se acompanhar por este aviso.

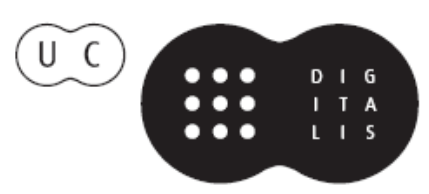




\section{O Livro do Tempo: Escritas e reescritas}

\section{Teatro Greco-Latino e sua recepção I}

Maria de Fátima Silva, Maria do Céu Fialho \& José Luís Brandão (coords.)

IMPRENSA DA UNIVERSIDADE DE COIMBRA

ANNABLUME 


\title{
El anciano SiRviente de Fenicias ${ }^{t}$ \\ (The old servant in Phoinissae)
}

\author{
Carmen Morenilla (Carmen.Morenilla@uv.es) \\ Universidad de Valencia, España
}

\begin{abstract}
Resumen - Desde la edición de Fenicias de Mastronarde se cuestiona la identidad del anciano que acompaña a la joven Antígona en la escena de la azotea. Nos proponemos estudiar los rasgos más relevantes de la caracterización de este personaje en comparación con otros similares para poder llegar a conclusiones sobre su pertenencia a uno u otro tipo de personaje secundario.

Palabras clave - Eurípides, Fenicias, pedagogo, personaje secundario.
\end{abstract}

Aвstract - The identity of the elder that is with Antigone in the roof scene is been argued since Mastronarde's edition of Euripides' Phoenissae. This paper provides an careful depiction of the portrayal of this character and an analysis of the most relevant traits of him in comparison with other similar group of secondary characters in order to identify him as a member of one group or another of secondary characters.

Keywords - Euripides, Phoenissae, secondary characters.

1. Fenicias es una obra peculiar en el conjunto de la producción euripidea. La historia de su recepción ha sufrido grandes vaivenes. Fue una de las tragedias de mayor éxito, ya fue una de las más representadas, sea completa, sea alguna de sus partes líricas en actuaciones que compilaban cantos de mayor lucimiento para el intérprete durante la Antigüedad, lo que, sin duda, provocó que se realizaran modificaciones interesadas en los textos. Posteriormente formó parte de las nueve tragedias escolares de Eurípides y más tarde también de la triada bizantina, lo que comportó que aparezca en más de 200 manuscritos y que conservemos pasajes en un buen número de fragmentos, y que en esa misma época, precisamente por esa inclusión en las sucesivas selecciones escolares, fuera objeto de múltiples comentarios, estudios, intentos de repristinación, etc.

Posteriormente, como ha sucedido con Hécuba hasta hace pocos decenios, en los que sólo entonces se ha despertado el interés por esa tragedia llena de violencia y de desesperación, tan apreciada en épocas anteriores, tampoco Fenicias, frente a la fortuna de épocas pasadas, gozó de mucho aprecio ni por parte de dramaturgos que quisieran reponerla, ni por parte de los estudiosos. Y cuando los investigadores le han prestado atención, con frecuencia ha sido para

${ }^{1}$ Este trabajo se enmarca en el proyecto de I+D FFI2015-63836-P del Ministerio de Economía y Competitividad de España. 
cuestionar la autenticidad de algún aspecto de la tragedia, desde versos sueltos hasta escenas completas, en muchos casos con razón, pero no siempre.

De antiguo se ha cuestionado la extención de esta tragedia, la más larga de las conservadas. Y hay consenso científico en considerar que hay escenas espúreas al final, así como algunos versos de otros lugares, algunos tan significativos como los dos versos iniciales ${ }^{2}$. En ello han sido fundamentales las ediciones comentadas de estudiosos como Valckenaer (1755), que empezaron a dudar de la filiación euripidea de diversos versos, en primer lugar versos sueltos y algunos dobletes y tripletes, pero sin llegar a realizar un estudio general que atañese a toda la estructura general de la obra, como sí que hicieron después otros estudiosos $^{3}$. Desde la edición de Hermann (1840) la tragedia ha sido duramente criticada por su supuesta falta de diseño unitario y por la presencia de elementos que se considera desgajados de la acción principal ${ }^{4}$.

Este ambiente generalizado de aceptación de intromisiones, de intercalación de versos o escenas ha provocado que el ánimo censor se aplicara a diversas escenas, incluso a personajes. Este fenómeno se produce especialmente en las obras de Eurípides y en Fenicias en particular. No sucede lo mismo con las obras de Esquilo o de Sófocles. Pensemos, por ejemplo, en Siete contra Tebas, con respecto a cuyo final, a partir del v. 1004, la comunidad científica casi con unanimidad ha aceptado que es espúreo, que fue compuesto por un autor posterior que quiso vincular la obra con Antígona, circunstancia que también aquí se produce, pero con la complejidad añadida de que Eurípides sí conocía la Antígona de Sófocles, por lo que las alusiones pueden ser suyas, a lo que contribuye la complejidad de la trama en este punto. Fijémonos en el argumento que Lesky da para dudar ante la expurgación de esas alusiones:

La redacción de la parte final, sobrecargada de motivos, resultaría mucho más límpida si tuvieran razón los que afirman que habría que suprimir todos los versos referentes al entierro de Polinices. Pero ofrece reparo sacar de la obra un motivo que, mediante la obra de Sófocles, ya estaba íntimamente unido al personaje de Antígona. (2001: 329)

${ }^{2}$ A este respecto hay una muy abundante bibliografía. Ya Kitto 1939: 104-111 había analizado las interpolaciones de la escena final. Un estudio detallado sobre las interpolaciones en el texto de Fenicias que revela que estas se incorporaron para aproximarlo argumentalmente a la Antigona y el Edipo en Colono de Sófocles es el de Fränkel 1963, quien atetiza los vv. 869-880, 886-890, 1104-1140, 1242-1258, 1307-1334, 1597-1614, 1645-1682, 1704-1707, 1737-1766, y algunos versos sueltos; en la misma línea Dos Santos Alves 1975, quien hace un exhaustivo análisis de los pasajes problemáticos; también Hose 1990: 63-74. Por contra, consideran auténticos la mayoría de los versos, entre otros, Conacher 1967: 92-101, Mastronarde 1978: 105-108, y Valgiglio 1961, quien los analiza desde presupuestos psicológicos.

${ }^{3}$ Se cuestionaron la estructura editores como Morus (1771), Boeckh (1808), Hartung (1843-4), Leidloff (1863) o Paley (1879), entre muchos otros.

${ }^{4}$ Por sólo citar una edición, la de Paley (1879: 6-7), considera que en realidad Fenicias tiene realmente un doble argumento. 
Esta aceptación de una interpolación en el final de Siete no comporta que se intente eliminar otros pasajes de la obra que a nosotros nos pueden resultar extraños, pesados, innecesarios. Nos pueden resultar todo eso a nosotros, con nuestra sensibilidad actual. En cambio sí se hace con las tragedias de Eurípides, particularmente con las que son tachadas de abigarradas, en las que el autor ha acumulado escenas y personajes con un criterio que se considera muy laxo, de manera que se opina que cualquiera pudo haber introducido en esa estructura tan abierta algo de su propia cosecha. Así es, sin duda, en algunas ocasiones, pero no en todas las ocasiones en las que algún estudioso cree ver algún verso, motivo o personaje que considera no adecuado para la obra o para el autor. Pero nosotros negamos la mayor: nosotros nos sumamos a la opinión de Aélion, que ya en 1983 defendía que la estructura de las tragedias de Eurípides más abigarradas no es arbitraria, sino que sigue un plan claramente fijado por el autor y que, en opinión de esta malograda estudiosa, está marcado por el diferente concepto de destino de Eurípides con respecto a Esquilo y a Sófocles, particularmente en sus últimas tragedias 5 .

2. Posterior cronológicamente a sus Suplicantes y, posiblemente, muy próxima a su Antígona (de la que sólo conservamos algunos fragmentos), las Fenicias se data entre los años 412 a. C., fecha de su Andrómeda y Helena (la primera sólo conservada fragmentaria), a las que fue posterior, y el 408 a.C., fecha de la marcha de Eurípides a Macedonia, donde muere el 406, a la que es anterior. Este margen se puede ver restingido a los años 409 ó 408, siempre que aceptemos la información de un escolio a Ranas, en el que el escoliasta comentaba que bien podía Aristófanes haber utilizado para su parodia la más reciente Fenicias en lugar de la Andrómeda o la Helena.

Se trata de unos años ésos, los que van del 411 al 408 a. C., turbulentos, que nos trasladan a una Atenas cuyo ambiente tenso parece recrear esta tragedia, con el asedio del ejército argivo y la amenaza de un final desastroso, algo que finalmente se dio tanto en la escena como unos años después en la realidad histórica ateniense ${ }^{6}$.

En nuestra opinión la progresiva modificación de la técnica dramática por parte de Eurípides es consecuencia de su visión del ser humano y del mundo,

${ }^{5}$ Aélion 1983: 69-85.

${ }^{6}$ La derrota de la flota ateniense en Sicilia, a la par que un optimismo exultante entre los espartanos, que veían muy cerca su victoria final, provocó en los aliados atenienses frecuentes deseos de separarse de la Liga; los atenienses, tras el inicial estupor, reaccionaron y crearon el Consejo de Ancianos, formado por 10 probouloi; además, la muerte de una gran masa de población en la batalla de Sicilia, de los sectores más humildes que formaban el cuerpo de remeros, afines a los sectores más demócratas, permite que los nuevos gobernantes tomen medidas que van anticipando el golpe del 411. Para estas cuestiones remitimos a Briant \& Lévêque (1995), en particular Briant para el período de la llamada guerra jonia (412-404), 1995: 116 ss. y Brulé para la situación social resultante, 1995: 185 ss. 
en el que nos presenta personajes que buscan comprender y escapar de una desgracia que ni se explican ni justifican. La falta de comprensión provoca a su vez que emprendan acciones que no les llevan al fin que desean, frustradas por otros personajes, por el azar o por una intervención divina: es el caso del intento de reconciliación de Yocasta, dos veces frustrado, o del deseo de cumplir con los ritos funerarios por parte de Antígona, que ha de ir modulando sus pretensiones (si es que realmente esta parte es de autoría euripidea). De esa incapacidad de actuar realmente se deriva el profundo patetismo y pesimismo que destilan estas tragedias, que va acompañado también de un manifesto deseo de saber, que veremos, por ejemplo, en la escena a la que nos referiremos ${ }^{7}$.

Todo ello, que creamos en la existencia de un plan bien urdido a pesar de las aparentes disgresiones y las variopintas peripecias, no impide que seamos conscientes de que el proceso de transmisión de esta obra fue especialmente complejo y que tanto el aprecio del público, que propició su reposición y la interpretación por cantantes profesionales de cantos desgajados, como la valoración positiva de los intelectuales que la escogieron como obra escolar la convirtieron en blanco perfecto para las interpolaciones de actores y de estudiosos. Sin negar, pues, la existencia de interpolaciones, pero convencidos de que la obra en sí misma tiene un sentido, el que Eurípides le quiso dar y que nosotros deberíamos buscar, nosotros buscamos entenderla y somos partidarios de expurgarla sólo en los casos en los que haya evidencias claras de intromisiones.

3. En otro lugar ya nos planteamos si debíamos aceptar las propuestas de eliminación, realizadas por algunos estudiosos ${ }^{8}$, de la escena a la que aquí nos referiremos, la siguiente a la resis inicial, la escena del diálogo entre el anciano sirviente y Antígona, llamada, no con total propiedad, teichoscopia, 88-201, escena muy estudiada, especialmente por su relación con la teichoscopia del canto tercero de Ilíada $a^{9}$. Esas propuestas parten de una interpretación posible de una

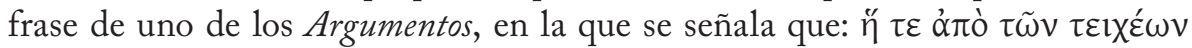

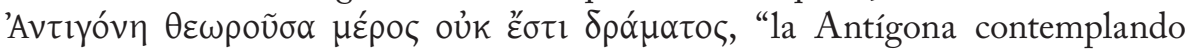

${ }^{7}$ Esta idea de que no es arbitraria la estructura de la tragedia, interpretada a partir de una perspectiva diferente, es también aceptada por Medda, para quien en la estructura de esta tragedia, con el gran desarrollo de las escenas particulares que podemos observar, se debe ver una combinación de innovación con respecto a las convenciones aceptadas, de tal modo que Eurípides lleva cada escena al máximo de efectividad posible, junto con un complicado y sutil juego de referencias a obras anteriores de otros dramaturgos, pero también de Homero, lo que confiere a la obra una densidad fuera de lo habitual (2010 $: 11$ s.).

${ }^{8}$ Verrall (1895), o mucho más cerca Dihle (1981), la atetizan siguiendo a Valckenaer quien considera la escena inorgánica para el desarrollo argumental. Mastronarde, Diggle, Medda, entre otros la consideran auténtica en tanto que introduce a Antígona, personaje que luego acompañará a su madre al campo de batalla, y contextualiza la situación de la ciudad de Tebas más allá de la historia del linaje y del enfrentamiento fratricida que interesa a Yocasta y por eso es lo que relata en el prólogo. Cf. para más detalle Morenilla 2013a: 25-51.

${ }^{9}$ Lo ha hecho, por ejemplo, Gonçalves 2001: 141-170. 
desde las murallas no es parte del drama”. Una frase ambigua, que puede ser interpretada de otras maneras, como también han hecho otros estudiosos.

Situémonos en la escena. Estamos en el prólogo, la escena que nos interesa precisamente acabará con el anuncio de la entrada del coro de mujeres fenicias. Como en otras tragedias de Eurípides, y no sólo en las denominadas tardías, el prólogo está formado por dos escenas, la primera una resis, un soliloquio de la heroína, al que sigue un diálogo. Aquí Eurípides innova en diferentes aspectos, y no sólo en el argumento. En primer lugar no podemos afirmar que en Fenicias Yocasta sea la protagonista, de hecho no parece que haya un personaje individual que lo sea, sino que el protagonismo descansa en el desdichado linaje, en sus sucesivos eslabones que renuevan las desgracias de las que se hacen acreedores ${ }^{10}$. Sin duda a ello se debe la peculiar estructura y la constelación de personajes de la tragedia, en la que vemos aparecer figuras que en las versiones dramáticas anteriores en ese momento de la acción ya habían muerto o habían desaparecido de Tebas. Yocasta no aparece en Siete contra Tebas, tragedia en la que se habla de la sepultura de Edipo; en todo caso, ninguno de los dos tienen relevancia alguna. Y en Edipo Rey asistimos al suicidio de Yocasta y probablemente al exilio de Edipo, personajes que no aparecen en Antígona. En cambio aquí, lo que probablemente provocara en el auditorio una buscada sorpresa, aparecen en escena y tienen relevancia dramática, particularmente Yocasta, pues, aunque no se la pueda considerar la protagonista, está presente y activa dramáticamente hasta el final de la obra, al final como cadáver, provocando, junto con sus hijos, los lamentos del éxodo ${ }^{11}$.

$\mathrm{Y}$ a esa resis en la que Yocasta explica los antecedentes tanto familiares como dramáticos, en la que aporta información muy relevante sobre la interpretación que del mito hace aquí el autor ${ }^{12}$, sigue un diálogo en el que no participa ella, como

${ }^{10}$ Mucho se ha discutido si en Fenicias hay realmente un personaje al que se pueda considerar principal. Autores como W. Riemschneider incluso llegaron a postular la idea de que la ciudad de Tebas en sí era el verdadero "héroe" de esta tragedia euripidea, en una interpretación que, por otra parte, podría estar quizás distorsionada por la ideología nazi de la época en la que se esbozó, en opinión de autores como Mastronarde, que en su comentario $\left(2004^{4}: 10\right.$ s.) también insiste en esa falta de personaje principal, en su opinión debido al deseo de explorar una visión trágica del mundo generalizada.

${ }^{11}$ Este treno, poco problemático en cuanto a su atribución a la mano de Eurípides, que ha sido calificado por Mastronarde (20044: 553) como una efusión lírica de dolor que equilibra estructuralmente las escenas líricas de la primera parte de la obra, muy probablemente, como ya han sugerido algunos (entre ellos Diggle en su edición), sea la escena final de la tragedia junto al dueto de Antígona y Edipo, vv. 1539-1581, un Edipo fantasmal que, más que llamado, aparece invocado por su hija ante la puerta de palacio, proyectando a través del texto una imagen que nos recuerda la figura de la sombra de Darío invocada en su tumba por Atosa en los Persas de Esquilo. La imagen de aquella Yocasta, sorprendentemente aún con vida en el prólogo, enlutada y con el cabello cortado, como exige el duelo, cobra ahora un sentido pleno por la aparición próxima a lo fantasmal de un Edipo.

${ }^{12}$ Cf., entre otros, Hamamé 2013: 129-140 y López Férez 2014: 239-259. 
sí sucedía en Andrómaca o en Helena, sino Antígona y el sirviente, el personaje que aquí nos interesa. Podría parecer que no hay relación entre ambas escenas, pero Eurípides ha creado un sutil nexo entre ellas: al acabar el parlamento Yocasta indica que ha enviado a un sirviente al campamento enemigo para pedirle a Polinices que parlamente con su hermano, para lo que la madre había conseguido una tregua, y ese sirviente es el que ahora acompaña a Antígona. Con ello Eurípides, que ya nos ha puesto en situación con las palabras de Yocasta, por las que sabemos que los enemigos rodean la ciudad, ahora, en esta peculiar escena, nos va a describir el espacio extraescénico de un modo muy original, puesto que en ella vemos la reacción emocional de la joven: la información concreta sobre el despliegue del ejército atacante por parte del anciano nos es transmitida junto con la reacción que provoca en la joven, incluyendo la reacción ante la visión del hermano. El anciano que acompaña a Antígona conoce bien la identidad de los atacantes, pues, como él mismo indica, ha estado como emisario en el campo argivo, donde ha podido ver los emblemas de sus escudos, lo que le permite ahora identificar a sus portadores, aun cuando éstos vayan ocultos bajo yelmo y armadura.

Se inicia, pues, la escena con la aparición de este anciano que acompaña a Antígona y que, además de informar, tiene la misión de velar por su seguridad en una sitación de inminente asalto de las tropas enemigas y, sobre todo, por salvaguardar su decoro ante cualquier encuentro desafortunado, ya que, a pesar de su condición de joven parthenos, Antígona ha abandonado las dependencias de las doncellas resuelta a encaramarse a la azotea y poder contemplar desde ella el despliegue del ejército argivo. Y una vez que ha respondido a las preguntas de Antígona sobre la identidad de los atacantes, y ante el tumulto de mujeres que se aproxima al lugar, que no serán otras que las jóvenes fenicias que conforman el coro, el anciano insta a Antígona a que descienda y regrese al interior de casa, a las dependencias de las doncellas, toda vez que ha satisfecho el anhelo de ver a su hermano, circunstancia ésta que le da pie para censurar la actitud y el comportamiento de las mujeres, en particular lo que hace referencia al tópico de las murmuraciones y maledicencias ${ }^{13}$.

En nuestra opinión, esta escena, junto aquella en la que la joven es llamada por su madre para que la acompañe al campo de batalla y junto al treno final, es clave para el desarrollo caracterológico de la Antígona de Fenicias. Su exclusión del conjunto de la obra nos dejaría a una Antígona excesivamente convencional, sin ese componente emocional impulsivo que también caracteriza a Edipo, no así a Ismene, un aspecto de su carácter bien conocido por todos y fijado con fuerza en su figura en el imaginario colectivo ${ }^{14}$.

${ }^{13}$ Sobre murmuraciones y maledicencias como motivo en otra obra tardía de Eurípides cf. Morenilla 2013b: 143-168.

${ }^{14}$ La proximidad de Antígona a Edipo y su distanciamiento de Ismene es algo que es apreciable incluso en la iconografía; a este respecto cf. Bañuls \& Crespo 2008: 257-292. 
4. Resuelto ya, en nuestra opinión, el asunto de la autoría de Eurípides de la escena, nos planteamos ahora la identidad del sirviente que acompaña a Antígona. Esta identidad no ha sido problema hasta la edición de Mastronarde. Todos los manuscritos lo presentan como "pedagogo", pero el prestigioso editor, reconocido estudioso de las Fenicias, lo problematiza. Señala:

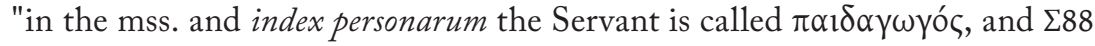

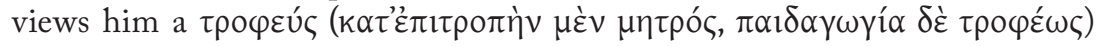

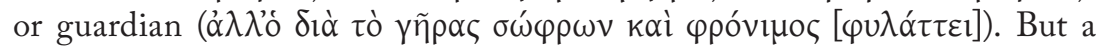
pedagogue is the slave who accompanies and oversees a boy from the age of

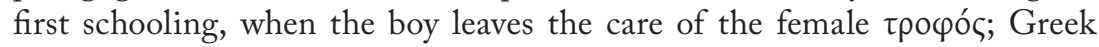
girls remained in the care of the nurse throughout childhood and are often attended by the nurse even after marriage (as Deianira, Phaedra, Medea, Herminone in tragedy). From the text we can see that Ant.'s companion is an old, trusted retainer, solicitous of the family; he is to be termed $\theta \varepsilon \rho \alpha \dot{\alpha} \pi \omega v$ or

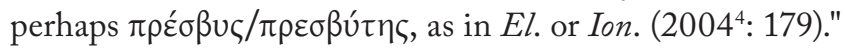

Como por otra parte era de esperar, otros editores le han seguido, como es el caso de Diggle o de Medda. Nosotros, sin embargo, no vemos la necesidad de enmendar los manuscritos en este punto. No sólo no nos convencen los argumentos sino que creemos que no se entiende bien la función de ese personaje al rebajarlo a simple sirviente. Naturalmente que no se está hablando del "pedagogo de Antígona”: ya sabíamos que las muchachas no tenían pedagogo, no necesitaban ser compañadas fuera de casa, puesto que no salían de casa, salvo en ocasiones muy especiales, y sabíamos que de normal estaban acompañadas de su nodriza. Sin embargo en las tragedias, como veremos, aparece al menos un pedagogo acompañando a una mujer. Veamos rápidamente cómo aparecen en Eurípides los pedagogos y la función que realizan.

5. En cuatro ocasiones en las obras conservadas Eurípides saca a escena un pedagogo, en Medea, Electra, Ión y en Fenicias. En Medea se trata del pedagogo de sus hijos, pero apenas tiene papel en la obra más allá de presentar en escena a los niños, traer nuevas informaciones sobre los planes de Jasón y Creonte y ayudar a caracterizar a la nodriza mediante el contraste de la actitud de ambos.

Los de las tragedias Electra e Ión son los que tienen un papel más relevante en la acción dramática, especialmente en Ión. Ambos son los pedagogos de la generación anterior, del padre del joven junto al que aparecen. En Electra Eurípides saca al anciano pedagogo de Agamenón, que no se ha integrado en el nuevo genos, sino que, como Electra, vive apartado de palacio, haciendo de pastor. Él es el responsable de la anagnórisis de Orestes en un complejo proceso en el que ha de imponerse al escepticismo de Electra, quien atribuye a la senilidad del anciano sus opiniones. Después su papel asesor del joven Orestes es relevante en la acción, en el asesinato de Egisto primero y de Clitemnestra 
después, sobre todo en el de Egisto, para el que es esencial la información que $\operatorname{aporta}^{15}$.

El anciano sirviente que aparece en Ión y que acompaña a su señora, a Creusa, es el pedagogo del padre de ésta, de Erecteo, y de los cuatro es el que desempeña un papel más relevante, para lo que el autor crea un personaje original, con rasgos propios $^{16}$.

Tras la escena de reconocimiento de Ión por Juto como el hijo que Apolo le ha prometido, el coro de criadas de Creusa, que acompaña a su señora desde Atenas, entona un extraño canto coral, 676-724, en el que no se cree las afirmaciones de los personajes y ve conspiraciones y engaños. Tras ese canto coral entran en escena Creusa y el anciano pedagogo, presentado por ella como el pedagogo de su padre y ahora suyo.

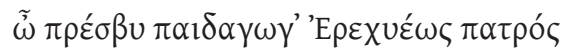

725

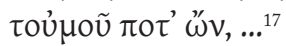

A esta presentación responde el anciano con unas expresiones que marcan su comportamiento:

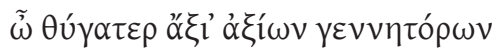
735

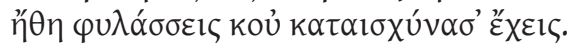

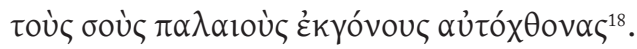

En sus primeras palabras el anciano se refiere a la nobleza de espíritu de Creusa, que le viene por la nobleza de posición de sus antepasados, de los que destaca la característica fundamental de la propaganda ateniense, la autoctonía, de la que este anciano será en la tragedia el máximo defensor.

Eurípides hace que Creusa manifieste el gran afecto y confianza que siente por el anciano. No se trata de un sirviente más de la casa de su padre: lo considera uno de sus philoi y quiere tenerlo junto a ella en lo bueno y en lo malo. Se trata de

${ }^{15}$ Aún así no es tan importante como el que desempeña el mismo pedagogo en la Electra de Sófocles: este autor hace que haya sido también el pedagogo del joven, de manera que su papel transmisor de los valores y principios del genos de Agamenón es esencial para comprender el pensamiento y la actuación de Orestes; esa es la razón también de que el anciano siga teniendo autoridad sobre él, aunque sea ya adulto, y que la iniciativa siga teniéndola el pedagogo, de modo que se convierte en la representación real del padre en ausencia de éste. Sobre el pedagogo de las dos Electra cf. Bañuls \& Crespo \& Morenilla 2006.

${ }_{16}$ Cf. Bañuls \& Morenilla 2014: 207-229 y con carácter general Synodinou 1977, quien ya señaló esa importancia.

17 “Anciano pedagogo de mi padre Erecteo, y ahora mío! ...”

18 "Hija, nobles costumbres de tus nobles progenitores conservas y no deshonras a tus mayores, que nacieron de la tierra!" 
una situación nueva en las obras de Eurípides ${ }^{19}$ : aquí vemos una señora cuidando de un sirviente suyo, cuya debilidad causada por la edad es hecha visible no sólo mediante las palabras, también por el bastón que lleva y por el modo de caminar, pues ha de ir ayudado por su señora.

En otras ocasiones Eurípides ha escenificado los efectos de la ancianidad, aunque en absoluto con la insistencia de este pasaje, debilidad que entra en contradicción con la frenética actividad que el anciano va a desarrollar a continuación: no sólo procederá a un interrogatorio minucioso, que irá acrecentando la tensión hasta que Creusa rompa su silencio de años y cuente su doloroso secreto, sino que será el mayor impulsor del castigo que, en su opinión, deben recibir los traidores, Juto e Ión. El coro pero sobre todo el pedagogo son los que consideran insoportable para la honorabilidad de su señora la llegada a palacio del bastardo. Es Creusa quien, a pesar de estar profundamente afectada por la situación, va rechazando las tremendas propuestas del anciano: primero quemar el templo de Apolo, después matar a Juto. Al final el pedagogo conseguirá que su señora le autorice a matar al joven bastardo, lo que efectivamente se propondrá realizar, pero Apolo lo frustrará.

En una obra en la que se cuestiona la política basada en la autoctonía exarcerbada que lleva a la exclusión de personas que han prestado o pueden prestar servicios a Atenas, como es el caso de Juto con respecto a hechos pasados y de Ión con respecto al futuro, es el pedagogo de Erecteo el que se convierte en el más puro defensor de esos supuestos valores de la casa de Erecteo. En unos momentos muy delicados para Atenas, cuando la población está sufriendo los desastres de la guerra, probablemente tras la terrible derrota de Sicilia ${ }^{20}$, Eurípides ofrece una obra en la que los personajes no entienden la situación en que están y al actuar se equivocan y provocan reacciones no deseadas, como zarandeados por el destino, pero en la que se rehabilita a Apolo y al oráculo de Delfos, que se presenta como certero y como protector de Atenas, y en la que se cuestiona la propaganda oficial ateniense, utilizada como argumento para negar los derechos de ciudadanía a sectores amplios de la sociedad.

Salvo en el caso de la tragedia Medea, en la que el papel del sirviente fiel está representado por la nodriza y el pedagogo de los niños tiene un papel muy limitado, en las otras dos obras que hemos muy rapidamente comentado al pedagogo confía Eurípides funciones relevantes, sólo adecuadas a personas en las que se tiene una gran confianza, asentada con los años y que requieren de él prudencia y buen tino. Es el caso del anciano pedagogo de la tragedia Electra, que será quien reconozca al extranjero, de un modo que nos recuerda mucho el reconocimiento de Odiseo por Euriclea; pero además a él se le encomendará la

\footnotetext{
${ }^{19}$ Brandt 1973: 83.

${ }^{20}$ Mayoritariamente se data la obra en el 414.
} 
misión de acompañar a los jóvenes recién llegados a presencia de Egisto. En el caso de la tragedia Ión es el anciano pedagogo de Erecteo, ahora acompañante de Creusa, el que toma la iniciativa en el proceso de decisión sobre lo que se debe hacer y el que se encargará de llevar a cabo un acto de tal envergadura y que precisa tanta confianza como el intento de asesinato de Ión, del supuesto hijo del rey Juto. Unos años después, en nuestra opinión, Eurípides vuelve a echar mano de esa figura, la del pedagogo, para la realización de unos trabajos que exigen confianza, como son llevar las treguas, primero, y velar por la joven Antígona a la par que le informa sobre los caudillos del ejército enemigo. El escolio citado por Mastronarde lo ve muy bien cuando señala que el anciano, que por su edad es sensato y prudente, vigila por el bien de la muchacha.

6. Efectivamente, la misión que antes le encomendó Yocasta, la de llevar las treguas a través del campamento enemigo hasta Polinices y de volver con la respuesta de éste de nuevo entre las huestes enemigas no podía ser realizada por cualquier sirviente, es una simple cuestión de lógica. Se precisaba una persona que fuera claramente reconocible por Policines, a pesar de la ausencia de casa, y que gozara de la suficiente confianza y respeto de éste como para poder atravesar el campo enemigo sin ser acusado de espía y sobre todo para poder comparecer ante el joven e influir en su ánimo. Una persona de total confianza de la madre, puesto que ella en persona no podía hacer ese trabajo.

Pero además, y esto es lo que aquí nos interesa, en la escena en la que aparece el anciano se muestra como un hombre sensato y prudente, que, al mismo tiempo que informa a la joven parthenos, vela por su seguridad $y$, sobre todo, salvaguarda su decoro ante cualquier encuentro desafortunado, como queda claro en las primeras y en las últimas palabras de la escena, en boca del anciano.

Antígona ha conseguido permiso de su madre para abandonar las dependencias de las doncellas y encaramarse a la azotea para poder observar desde ella el despliegue del ejército argivo. Así lo dice el sirviente, que sale el primero porque no quiere que nadie la vea y eso pueda ser objeto de reproche, 88-95:

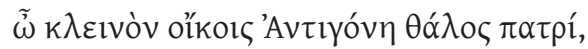

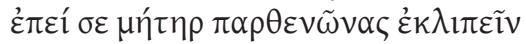

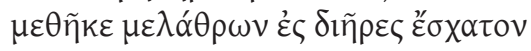

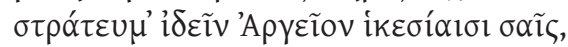

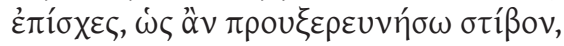

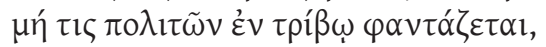

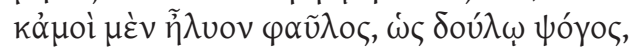

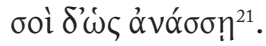

21 " Antígona, ilustre retoño para la casa de tu padre! Puesto que tu madre te permitió 
A continuación indica porqué conoce perfectamente la distribución y la composición del ejército atacante y sigue diciendo (99s.):

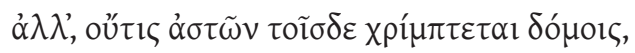

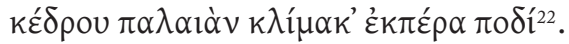

Esta salida a escena retardada de Antígona es muy llamativa, tanto que no han faltado estudiosos que han querido ver en ella una necesidad de tiempo por parte del actor protagonista, que habría representado el papel de Clitemnestra en la primera escena del prólogo, y ahora representaría el de Antígona. En absoluto es necesario que el actor protagonista interprete esos dos papeles, por dos razones: en primer lugar, en una escena posterior aparecerán juntas las dos mujeres $^{23}$, pero además también en otras tragedias el deuteragonista puede tener intervenciones líricas, y más si son cortas, como las que en esta escena canta Antígona.

Esa salvaguarda del honor de la joven se vuelve a manifestar en las palabras finales del anciano. Tras responder a las preguntas de Antígona sobre la identidad de los atacantes y después de que ella haya podido ver, mejor dicho entrever a su hermano, ante el tumulto de mujeres que se aproxima al lugar, que después sabremos que son las jóvenes fenicias, el sirviente insta a Antígona a que descienda y regrese al interior de casa, a las dependencias de las doncellas, donde es su obligación permanecer (193-195):

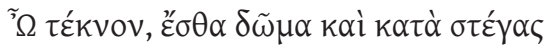

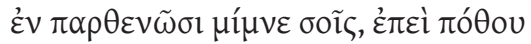

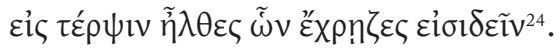

A ello sigue una crítica de carácter general en boca del anciano sobre la facilidad con la que las mujeres se dan a la maledicencia, como en otras muchas ocasiones vemos en las tragedias de Eurípides, y que aquí es la causa de que al comienzo de la escena saliera él solo para comprobar que nadie podía verles y ahora lo es de que la haga entrar en casa sin más dilación. Tanto el retraso en

abandonar las habitaciones de las doncellas y subir al último piso del palacio, para así contemplar el ejército argivo movida por tus ruegos, espera, que voy a inspeccionar el terreno, no sea que algún ciudadano se nos aparezca en el camino y se suscite un vil reproche contra mí, como esclavo, y contra ti, como princesa”. tu pie".

22 "Ea! ningún ciudadano se acerca a este palacio. La vieja escalera de cedro franquea con

${ }^{23}$ Lo que tampoco sería inconveniente definitivo, puesto que un mismo personaje podía ser representado por varios actores.

${ }_{24}$ “Hija, entra en casa y bajo techo, en las habitaciones de las doncellas, quédate, puesto que satisfaciste el deseo de lo que necesitabas contemplar!" 
salir a escena y las razones que el sirviente da de ello, así como las que le llevan a apremiar en el regreso a las dependencias de las doncellas son motivo suficiente para que debamos ver en él una persona merecedora de la total confianza de Yocasta, papel que cuadra muy bien a un pedagogo, al que se encomendó la función de velar por los niños cuando abandonan los brazos de las nodrizas.

Pero hay un elemento más en sus intervenciones que nos hacen que veamos en él a una persona que se toma muchas confianzas, más de las que se admitiría en un simple sirviente. Nos referimos a la afirmación que hace en los vv. 154 s., en los que replica a Antígona que no están faltos de razón los atacantes:

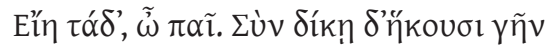

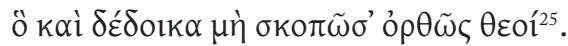

En una circunstancia como la que se nos está presentando en esta descripción del espacio extraescénico, donde se detallan los preparativos para entrar en combate y tomar la ciudad, no es esperable que un simple sirviente haga una afirmación de este tipo, exponiéndose a las iras de su joven señora, que acaba de desear la muerte de Partenopeo. Sólo una persona en la que se supone la suficiente cercanía a la familia, particularmente a los dos hermanos varones, cabría aceptar un comentario tal.

7. En conclusión, no sólo no creemos que no sea necesario el cambio en cuanto a la identificación del personaje que Mastronarde introdujera y otros han seguido, sino que creemos que ese cambio de identidad manifiesta que no se ha comprendido bien la función del personaje, tanto la que desarrolló fuera del escenario como la que desarrolla después acompañando a la joven Antígona y velando por su seguridad y decoro.

25 "Sea así, hija. Pero con justicia llegan a esta tierra, lo que también temo que los dioses observen con rectitud". 


\section{Bibliografía}

\section{Ediciones}

Mastronarde, D. J. (20044), Euripides: Phoenissae. Cambridge: Cambridge University Press.

Medda, E. (2010³), Euripide: Le Fenicie. Milán: Bur Rizzoli.

Valckenaer, L.C. (1755), Euripides Tragoedia Phoenissae. Franequer: Brower.

Morus, S. F. N. (1771), De Euripidis Phoenissis. Lipsia: Langenheim.

Boeckh, A. (1808), Graecae Tragoediae principum, Aeschylis, Sophoclis, Euripidis, Heiderlberg: Mohr et Zimmer.

Hartung, J. A. (1843/44), Euripides Restitutus, II. Hamburgo: Perthes.

Leidloff, H. (1863), De Euripidis Phoenissarum argumento atque compositione. Holzminden: Gymn. Pr.

G. Hermann (1840), Euripides Phoenissae. Lipsiae.

Paley, F. A. (1879), The Phoenissae of Euripides. Londres: Deighton.

\section{Bibliografía SECUndaria}

Aélion, R. (1983), "La technique dramatique d'Euripide et sa conception de la destinée humaine", in Jouan, F. (ed.), Visages du destin dans les mythologies. Mélanges Jacqueline Duchemin. Paris, Les Belles Lettres: 69-85.

Alves, M. dos Santos (1975), As Fenicias. Coimbra: Instituto de Alta Cultura. Centro de Estudos Clássicos e Humanísticos.

Bañuls, J.Vte., Crespo, P. (2008), "El vestuario de Antígona: aproximación a una caracterización física del personaje", in De Martino, F. (ed.), Abiti da Mito. Bari, Levante Editori: 257-292.

Bañuls, J.Vte., Crespo, P., Morenilla, C. (2006), Electra de Sófocles y las primeras recreaciones hispanas. Bari: Levante Editori.

Bañuls, J.Vte., Morenilla, C. (2014), "El pedagogo de Ión". A la sombra de los héroes, in De Martino, F. Morenilla, C. (eds.). Bari, Levante Editori: 207 $-229$.

Brandt, H. (1973), Die Sklaven in den Rollen von Dienern und Vertrauten bei Euripides. Hildesheim-New York: Olms.

Briant, P., Lévêque, P. (1995), Le Monde Grec aux temps classiques, t. 1, Le Ve siècle. Paris: PUF.

Dihle, A. (1981), Der Prolog der Bacchen und die antike Überlieferungsphase des Euripides-Textes. Heidelberg: Sitzungsberichte der Heidelberger Akademie der Wissenschaften. 
Conacher, D. J. (1967), “Themes in the Exodus of Euripides' Phoenissae”, Phoenix 2: 92-101.

Fränkel, E. (1963), Zu den Phoinissen des Euripides. München: BAW.

Gonçalves, C. (2001), "O motivo épico da teichoscopia. Confronto do modelo de Iliada 3.166, 242 e de Fenicias", Humanitas 53: 141-170.

Hamamé, G. N. (2013), "Fenicias de Eurípides: concepción agonal de espacio y tiempo en prólogo y párodos (vv.1-260)”, Synthesis 20: 129-140.

Hose, M. (1990), "Überlegungen zur Exodos der Phoinissai des Euripides", Würzburger Jahrbücher für die Altertumswissenschaft 16: 63-74.

Kitto, H. D. F. (1939), “The final scenes of the Phoenissae”, Classical Review 53: 104-111.

Lesky, A. (2001), La tragedia griega (trad. del original alemán de 1958). Barcelona: El acantilado.

López Férez, J. A. (2014), "Las Fenicias de Eurípides: tragedia, mito, pensamiento, léxico", Fotunatae 25: 239-259.

Morenilla, C. (2013a), "La Antígona de Fenicias o la larga sombra de la Antígona de Sófocles", Humanitas 65: 25 - 51.

Morenilla, C. (2013b), "La Andrómaca de Eurípides, una tragedia en clave coral", $C F C(g)$ 23: 143-168.

Synodinou, K. (1977), On the Concept of Slavery in Euripides. University of Ionnina.

Valgiglio, E. (1961), L'Essodo delle Fenice di Euripide. Torino: Università di Torino.

Verrall, A.W. (1895), Euripides the Rationalist. Cambridge: Cambridge University Press.

Yoon, F. (2012), The Use Anonymous Characters in Greek Tragedy. Leiden-Boston: Brill. 